\title{
Is Body Mass Index Associated With the Development of Age-Related Hearing Impairment in Koreans? The Korean National Health and Nutrition Examination Survey 2009-2012
}

\author{
Da Jung Jung $\cdot$ Jeong Hun Jang $\cdot$ Kyu-Yup Lee \\ Department of Otorhinolaryngology-Head and Neck Surgery, Kyungpook National University Hospital, \\ Kyungpook National University College of Medicine, Daegu, Korea
}

Objectives. The aim of this study was to evaluate whether body mass index (BMI) is associated with age-related hearing loss (ARHL) in the Asian elderly population.

Methods. Data from the Korean National Health and Nutrition Examination Survey 2009-2012 were used for the analyses. The pure tones at 0.5 and $1 \mathrm{kHz}$ of both ears of each subject were averaged to obtain the low-frequency, those at 2 and $3 \mathrm{kHz}$ were averaged to obtain the mid-frequency, and those at 4 and $6 \mathrm{kHz}$ were averaged to obtain the highfrequency. The average hearing threshold (AHT) was calculated as pure tone average at 4 frequencies in the better ear. ARHL was defined as the AHT $>25 \mathrm{~dB}$.

Results. Univariate analyses revealed an increase in the BMI tertile in men was associated with a decreased low-frequency threshold, while an increase in the BMI tertile in women was associated with decreased mid- and high-frequency thresholds. Multivariate analyses adjusted for confounders show no significant differences in low-, mid-, or high-frequency. There was no significant difference in the prevalence of ARHL by BMI tertiles. Linear regression analyses show no association between BMI and low-, mid-, and high-frequency or AHTs. The area under the receiver operating characteristic curve values for AHT was 0.515 in men and 0.522 in women. The logistic regression analyses showed no association between BMI and ARHL in either sex.

Conclusion. BMI is not advantageous for the prediction of ARHL. In future epidemiological studies, BMI as a covariate of obesity may be replaced by other active metabolic parameters that have better predictive ability of ARHL than BMI.

Keywords. Hearing; Body Mass Index; Metabolic Diseases

\section{INTRODUCTION}

The prevalence of age-related hearing loss (ARHL) gradually increases as the general population ages. ARHL is caused by a

\footnotetext{
- Received June 11, 2015

Revised August 5, 2015

Accepted August 10, 2015

- Corresponding author: Kyu-Yup Lee

Department of Otorhinolaryngology-Head and Neck Surgery, Kyungpook

National University Hospital, Kyungpook National University College of

Medicine, 130 Dongdeok-ro, Jung-gu, Daegu 41944, Korea

Tel: +82-53-420-5785, Fax: +82-53-423-4524

E-mail: kylee@knu.ac.kr
}

number of multifactorial processes such as ototoxic agents, trauma, metabolic disturbances, diet, and hormonal changes [1-3]. Metabolic diseases, such as diabetes mellitus (DM) and hypertension (HTN), are associated with vasculopathies in the stria vascularis of the cochlear duct [4].

Metabolic diseases such as DM, HTN, and dyslipidemia are correlated with obesity. Obesity is measured by body mass index (BMI), waist circumference, or body composition analysis using bioelectrical impedance analysis or dual X-ray absorptiometry. Among these indicators, BMI is most commonly used to assess obesity and is obtained by dividing a person's total body weight in kilograms by the square of their height in meters.

Copyright $@ 2016$ by Korean Society of Otorhinolaryngology-Head and Neck Surgery.

This is an open-access article distributed under the terms of the Creative Commons Attribution Non-Commercial License (http://creativecommons.org/licenses/by-nc/4.0)

which permits unrestricted non-commercial use, distribution, and reproduction in any medium, provided the original work is properly cited. 
The relationship between BMI and ARHL is controversial. Some studies have shown that BMI is associated with hearing loss in both sexes, while other studies have indicated that BMI is associated with hearing loss in only women [5,6]. One large study has shown an association between BMI and hearing loss; however, the hearing loss data in this study were gathered by hearing questionnaires [7]. Other studies show no association between BMI and hearing loss [8,9]. However, many investigators think that BMI is a definite risk factor of ARHL and they include BMI as a covariate in epidemiologic studies. The aim of this study was to evaluate whether BMI is associated with ARHL in the Asian elderly population.

\section{MATERIALS AND METHODS}

\section{Study population}

Data from the Korean National Health and Nutrition Examination Survey (KNHANES) 2009-2012 were used for the analyses. The KNHANES is a nationwide, multistage, stratified survey of a representative sample of the South Korean population conducted by the Korea Centers for Disease Control and Prevention. The total number of participants in KNHANES was 36,067 (Fig. 1). Data were excluded for the present analyses if the subjects were younger than 65 years of age $(n=21,050)$; they could not provide data regarding BMI $(n=4,557)$ and hearing evaluation $(n=4,583)$; they had external or middle ear disease $(n=836)$; they had brain disorders such as stroke $(n=1,330)$. Any subjects with asymmetric hearing results were also excluded $(n=614)$. More than a $15-\mathrm{dB}$ difference at $0.5,1,2$, or $4 \mathrm{kHz}$ was defined as asymmetric hearing. As a result, 3,097 participants were included in this study. Local ethical committee ap-

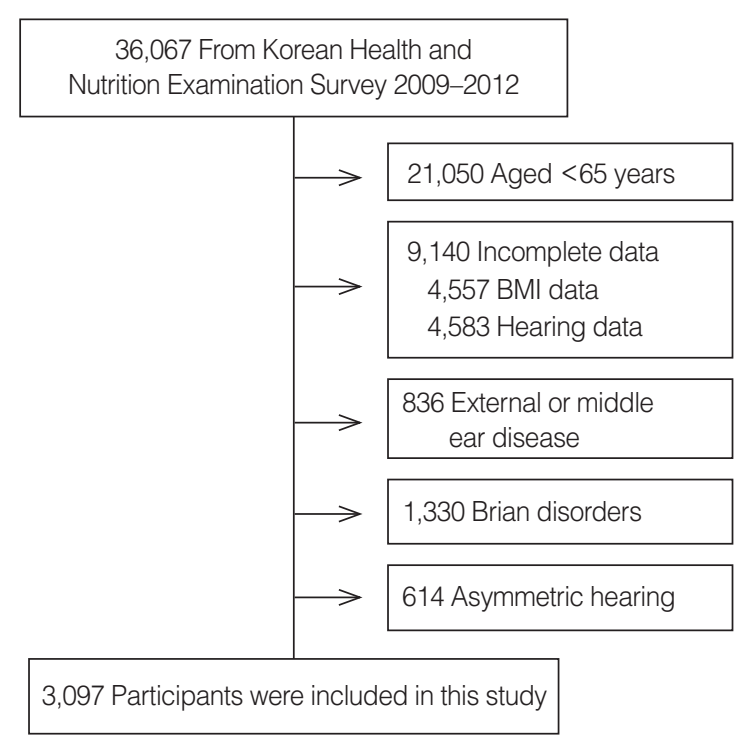

Fig. 1. Flow chart of the study participants. BMI, body mass index. proval was obtained for this study.

\section{Study variables}

Clinical and laboratory data collected from the participants during the health examination included the following: age (yr), sex, BMI $\left(\mathrm{kg} / \mathrm{m}^{2}\right)$, hemoglobin $(\mathrm{g} / \mathrm{dL})$, serum creatinine $(\mathrm{mg} / \mathrm{dL})$, total cholesterol (mg/dL), high-density lipoprotein cholesterol (mg/dL), triglyceride level (mg/dL), smoking behavior, and alcohol consumption.

BMI was calculated by dividing the total body weight in kilograms by the square of the participant's height $\left(\mathrm{kg} / \mathrm{m}^{2}\right)$. Participants were divided into 3 groups according to their BMI tertiles: the low tertile $\left(<21.9 \mathrm{~kg} / \mathrm{m}^{2}\right.$ for men and $<22.8 \mathrm{~kg} / \mathrm{m}^{2}$ for women); the middle tertile (21.9-24.5 kg/m ${ }^{2}$ for men and $22.8-$ $25.6 \mathrm{~kg} / \mathrm{m}^{2}$ for women); the high tetile $\left(>24.6 \mathrm{~kg} / \mathrm{m}^{2}\right.$ for men and $>25.6 \mathrm{~kg} / \mathrm{m}^{2}$ for women). We also analyzed the data using an age-based classification (65-69, 70-79, $\geq 80$ years), because $\mathrm{BMI}$ has been reported to decrease with the age [10].

DM was defined as a self-reported history of a DM diagnosis or a fasting glucose level of $\geq 126 \mathrm{mg} / \mathrm{dL}$. HTN was defined as an a systolic blood pressure of $\geq 140 \mathrm{mmHg}$, diastolic blood pressure of $\geq 90 \mathrm{mmHg}$, a self-reported history of HTN, or the use of anti-HTN drugs. Smoking behaviors were classified as current smoker, ex-smoker, or nonsmoker. The mean daily alcohol intake was defined by the Korean version of "standard drinking," which was based on the World Health Organization classification [11,12]. We classified the mean daily alcohol intake into 3 categories: abstinence (not having had an alcohol drink within the last year); moderate drinking (women, 0.1-19.99 g pure alcohol/day; men, 0.1-39.99 g pure alcohol/day), and heavy drinking (women, $\geq 20 \mathrm{~g}$ pure alcohol/day; men, $\geq 40 \mathrm{~g}$ pure alcohol/day).

Otological physical examinations and pure tone audiometry were performed as previously described [13]. None of these subjects were currently receiving medication that is associated with ototoxicity. Histories of explosive or occupational noise exposure were classified as positive or negative, according to the subjects' recall. An explosive noise was defined as a sudden loud noise, such as an explosion or gunshot. Exposure to occupational noise was determined according to whether the participants had worked in a location with loud machinery for $\geq 3$ months. Loud noise was defined by whether the participants had needed to raise his or her voice to have a conversation. The hearing thresholds were measured at 0.5, 1, 2, 3, 4, and $6 \mathrm{kHz}$. For both ears of each subject, the pure tone averages at 0.5 and $1 \mathrm{kHz}$ were averaged to obtain the low-frequency value, those at 2 and $3 \mathrm{kHz}$ were averaged to obtain the mid-frequency value, and those at 4 and $6 \mathrm{kHz}$ were averaged to obtain the high-frequency value. In the present study, the average hearing threshold (AHT) was calculated as pure tone average at 4 frequencies $(0.5$, 1,2 , and $4 \mathrm{kHz}$ ). ARHL was defined by AHT $>25 \mathrm{~dB}$ in the better ear. 


\section{Statistical analyses}

The data were analyzed using IBM SPSS Statistics ver. 20.0 (IBM Co., Armonk, NY, USA). The variables were expressed as mean \pm standard deviation and compared using $t$-tests. Categorical variables were expressed as counts and percentages. The Pearson chi-square test or the Fisher exact test was used to analyze categorical variables. For continuous variables, means were compared using the $t$-test or one-way analysis of variance, followed by a post hoc Tukey comparison. A correlation analysis was performed to assess the strength of the correlation between BMI and hearing threshold. Multivariate analyses using analyses of covariance, multiple linear regression, or multiple logistic regression were used determine the independent predictors of hearing thresholds or ARHL. Model 1 was unadjusted; model 2 was adjusted for age; model 3 was adjusted for age, smoking, mean daily alcohol intake, DM, HTN, exposure to explosive noise, and exposure to occupational noise. The data for linear regression analyses were expressed as mean $\pm \mathrm{SE}$. Discrimination, which is the ability of the model to differentiate between participants who have ARHL and those who do not, was examined using the area under the receiver operating characteristic curve (AUROC). AUROC analysis was also performed to calculate cutoff values, sensitivity, and specificity. The best cutoff risk point was defined from the maximum of the Youden index in the AUROC. The AUROC was calculated by using MedCalc ver. 11.6.1.0 (MedCalc, Mariakerke, Belgium). The level of statistical significance was set at $P<0.05$.

\section{RESULTS}

\section{Clinical characteristics of participants}

The mean age of the study participants decreased as the BMI tertile increased in both sexes (Table 1). The prevalence of DM and HTN increased the BMI tertile increased in both sexes. Current smoking in both sexes and AHT in women were associated with a high BMI tertile. There were no significant differences in exposure to occupational noise or explosive noise according to BMI tertiles in both sexes. The prevalence of ARHL was not associated with BMI tertile in either sex.

Association between $\mathrm{BMl}$ and hearing thresholds

In men, the low-frequency value decreased as BMI tertile in-

Table 1. Clinical characteristics of participants

\begin{tabular}{|c|c|c|c|c|c|c|c|c|}
\hline \multirow[b]{2}{*}{ Characteristic } & \multicolumn{4}{|c|}{ Men $(n=441)$} & \multicolumn{4}{|c|}{ Women $(n=591)$} \\
\hline & $\begin{array}{c}\text { Low } T \\
(n=441)\end{array}$ & $\begin{array}{l}\text { Middle } T \\
(n=442)\end{array}$ & $\begin{array}{l}\text { High T } \\
(n=441)\end{array}$ & $P$-value* & $\begin{array}{c}\text { Low T } \\
(n=591)\end{array}$ & $\begin{array}{l}\text { Middle T } \\
(n=591)\end{array}$ & $\begin{array}{l}\text { High T } \\
(n=591)\end{array}$ & $P$-value* \\
\hline Age (yr) & $72.6 \pm 4.8$ & $71.8 \pm 4.7$ & $70.9 \pm 4.4$ & $<0.001$ & $72.9 \pm 5.7$ & $72.0 \pm 5.0$ & $71.5 \pm 4.7$ & $<0.001$ \\
\hline Body mass index $\left(\mathrm{kg} / \mathrm{m}^{2}\right)$ & $20.2 \pm 1.4$ & $23.3 \pm 7.4$ & $26.5 \pm 1.6$ & $<0.001$ & $21.0 \pm 1.5$ & $24.2 \pm 7.5$ & $27.9 \pm 2.2$ & $<0.001$ \\
\hline Diabetes mellitus & $79(17.9)$ & $95(21.5)$ & $122(27.7)$ & 0.002 & $97(16.4)$ & $125(21.2)$ & $158(26.7)$ & $<0.001$ \\
\hline Hypertension & $198(44.9)$ & $252(57.1)$ & $321(72.8)$ & $<0.001$ & $333(56.3)$ & $385(65.1)$ & $444(75.1)$ & $<0.001$ \\
\hline Mean daily alcohol intake & & & & 0.117 & & & & 0.039 \\
\hline Abstinence & $134(30.4)$ & $123(27.9)$ & $121(27.4)$ & & $378(64.0)$ & 349 (59.1) & $365(61.8)$ & \\
\hline Moderate drinking & $184(41.7)$ & $211(47.8)$ & $225(51.0)$ & & $173(29.3)$ & $214(36.2)$ & $203(34.3)$ & \\
\hline Heavy drinking & $112(25.4)$ & $95(21.5)$ & $91(20.6)$ & & $24(4.1)$ & $14(2.4)$ & $13(2.2)$ & \\
\hline No data & $11(2.5)$ & $13(2.9)$ & $4(0.9)$ & & $16(2.7)$ & $14(2.4)$ & $10(1.7)$ & \\
\hline Smoking & & & & $<0.001$ & & & & 0.025 \\
\hline Nonsmoker & $61(13.8)$ & $62(14.1)$ & $75(17.0)$ & & $518(87.6)$ & $536(90.7)$ & $539(91.2)$ & \\
\hline Ex-smoker & $189(42.9)$ & $205(46.5)$ & $251(56.9)$ & & $19(3.2)$ & $20(3.4)$ & $26(4.4)$ & \\
\hline Current smoker & $181(41.0)$ & $163(37.0)$ & $112(25.4)$ & & $38(6.4)$ & $22(3.7)$ & $17(2.9)$ & \\
\hline No data & $10(2.3)$ & $12(2.7)$ & $3(0.7)$ & & $16(2.7)$ & $13(2.2)$ & $9(1.5)$ & \\
\hline Occupational noise & 0.082 & & & 0.082 & & & & 0.926 \\
\hline Exposure & $138(31.3)$ & $146(33.1)$ & $159(36.1)$ & & $48(8.1)$ & $38(6.4)$ & $35(5.9)$ & \\
\hline Nonexposure & $219(49.7)$ & $214(48.5)$ & $221(50.1)$ & & $437(73.9)$ & $443(75.0)$ & $445(75.3)$ & \\
\hline No data & $84(19.0)$ & $82(18.6)$ & $61(13.8)$ & & $106(17.9)$ & $110(18.6)$ & $111(18.8)$ & \\
\hline Explosive noise & & & & 0.676 & & & & 0.310 \\
\hline Exposure & $41(9.3)$ & $51(11.5)$ & $65(14.7)$ & & $30(5.1)$ & $29(4.9)$ & $27(4.6)$ & \\
\hline Nonexposure & $320(72.6)$ & $309(69.9)$ & $315(71.4)$ & & $457(77.3)$ & $452(76.5)$ & 456 (77.2) & \\
\hline No data & $80(18.1)$ & $82(18.6)$ & $61(13.8)$ & & $104(17.6)$ & $110(18.6)$ & 108 (18.3) & \\
\hline $\mathrm{AHT}(\mathrm{dB})$ & $30.1 \pm 17.4$ & $29.0 \pm 15.8$ & $28.1 \pm 14.8$ & 0.183 & $27.9 \pm 17.6$ & $26.7 \pm 16.2$ & $25.6 \pm 13.8$ & 0.041 \\
\hline $\mathrm{ARHL}$ & $248(56.2)$ & $250(56.7)$ & $238(54.0)$ & 0.115 & $292(49.4)$ & $271(45.9)$ & 279 (47.2) & 0.074 \\
\hline
\end{tabular}

Values are presented as mean \pm SD or number (\%).

$\mathrm{T}$, tertile; $\mathrm{AHT}$, average hearing threshold; $\mathrm{ARHL}$, age-related hearing loss.

${ }^{*} P$-values between males and females were tested by one-way analysis of variance for continuous variables and Pearson chi-square test or Fisher exact test for the categorical variables. 
creased (Fig. 2). There was a significant decrease in the low-frequency value of the high BMI tertile compared with the low BMI tertile. In women, the mid-frequency and high-frequency values decreased as BMI tertile increased. There were significant decreases in the mid-frequency and high-frequency values of the high BMI tertile compared with the low BMI tertile. However, multivariate analyses show no association between BMI tertile and the low-, mid-, or high-frequency values (Table 2).

In men, correlation coefficients between BMI and hearing thresholds were -0.046 for low-frequency, -0.020 for mid-fre- quency, -0.030 for high-frequency, and -0.034 for AHT values.

There were no significant correlations between BMI and hearing thresholds $(P=0.092$ for low-frequency, $P=0.446$ for midfrequency, $P=0.278$ for high-frequency, and $P=0.211$ for AHT). In women, the correlation coefficients between BMI and hearing thresholds were -0.057 for low-frequency, -0.093 for midfrequency, -0.108 for high-frequency, and -0.073 for AHT values. Although there were significant correlations between BMI and hearing thresholds, the correlations were weak $(P=0.016$ for low-frequency, $P<0.001$ for mid-frequency, $P<0.001$ for

Table 2. Multivariate analyses of hearing thresholds by body mass index tertile

\begin{tabular}{|c|c|c|c|c|c|c|c|c|}
\hline \multirow{2}{*}{ Model } & \multicolumn{4}{|c|}{ Men } & \multicolumn{4}{|c|}{ Women } \\
\hline & Low $T$ & Middle T & High T & $P$-value & Low T & Middle T & High T & $P$-value \\
\hline \multicolumn{9}{|l|}{ Model 2} \\
\hline Low-Freq & $24.2 \pm 0.7$ & $24.0 \pm 0.7$ & $23.0 \pm 0.7$ & 0.482 & $25.6 \pm 0.6$ & $25.8 \pm 0.6$ & $25.0 \pm 0.6$ & 0.659 \\
\hline Mid-Freq & $38.7 \pm 0.9$ & $38.2 \pm 0.9$ & $39.3 \pm 0.9$ & 0.690 & $33.4 \pm 0.7$ & $32.3 \pm 0.7$ & $32.0 \pm 0.7$ & 0.283 \\
\hline High-Freq & $58.8 \pm 0.9$ & $57.9 \pm 0.9$ & $59.3 \pm 0.9$ & 0.580 & $48.0 \pm 0.7$ & $46.8 \pm 0.7$ & $46.2 \pm 0.7$ & 0.201 \\
\hline \multicolumn{9}{|l|}{ Model 3} \\
\hline Low-Freq & $22.7 \pm 0.7$ & $22.3 \pm 0.7$ & $22.4 \pm 0.7$ & 0.909 & $24.7 \pm 0.6$ & $25.3 \pm 0.6$ & $23.6 \pm 0.6$ & 0.445 \\
\hline Mid-Freq & $37.7 \pm 1.0$ & $37.2 \pm 0.9$ & $38.5 \pm 0.9$ & 0.621 & $32.1 \pm 0.7$ & $30.9 \pm 0.6$ & $30.7 \pm 0.7$ & 0.241 \\
\hline High-Freq & $57.8 \pm 1.0$ & $57.1 \pm 1.0$ & $58.8 \pm 1.0$ & 0.451 & $46.6 \pm 0.7$ & $45.6 \pm 0.7$ & $45.3 \pm 0.7$ & 0.415 \\
\hline
\end{tabular}

Values are presented as mean \pm SE.

T, tertile; Freq, frequency.

Model 2 was adjusted for age and model 3 was adjusted for age, mean daily alcohol intake, smoking, diabetes mellitus, hypertension, exposure to explosive noise, and exposure to occupational noise.

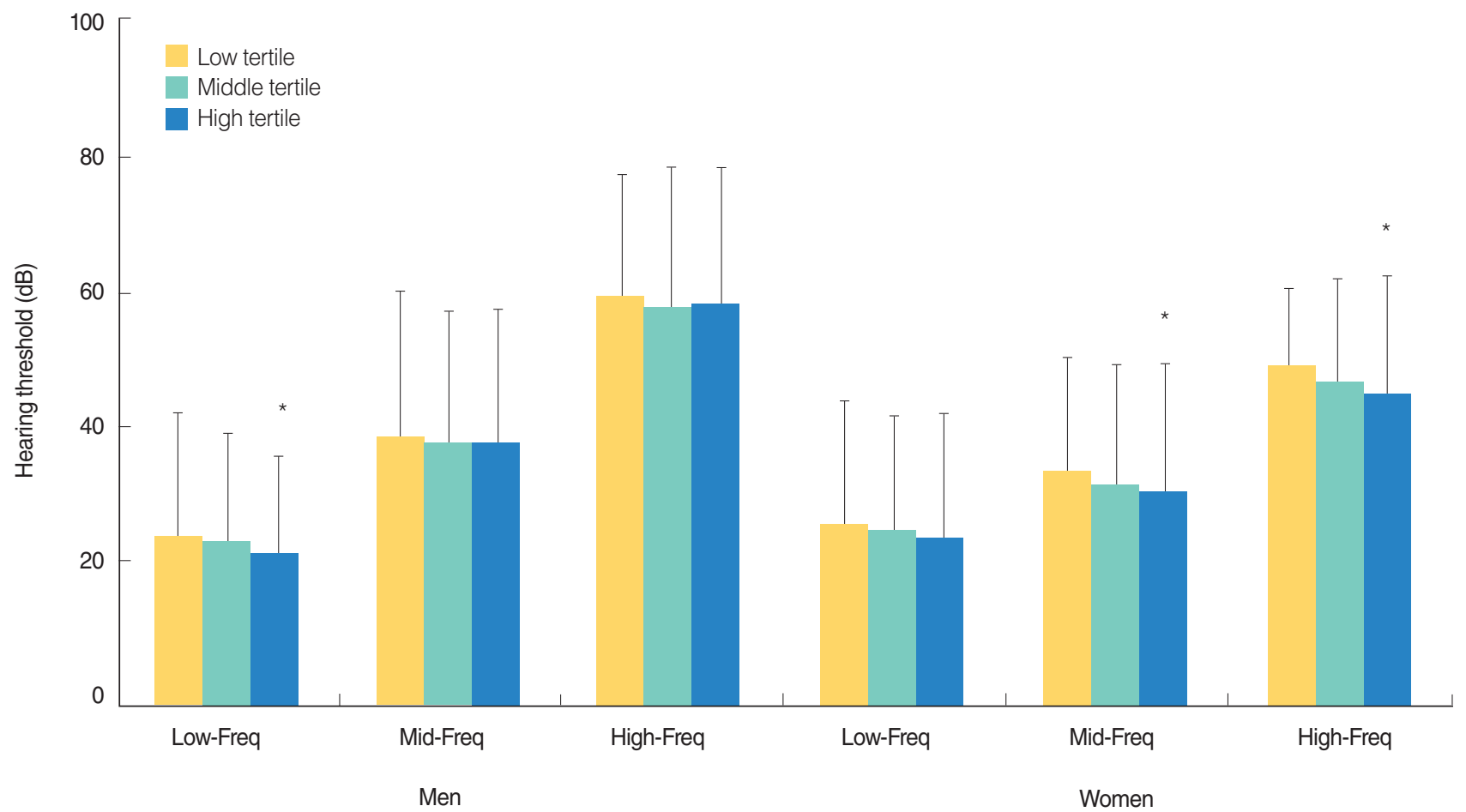

Fig. 2. Hearing thresholds according to body mass index tertile. Low-Freq trend, $P=0.021$ in men and $P=0.092$ in women; Mid-Freq trend, $P=0.467$ in men and $P=0.006$ in women; High-Freq trend, $P=0.412$ in men and $P=0.002$ in women. Freq, frequency. ${ }^{*} P<0.05$ compared to participants in the low tertile. 
high-frequency, and $P=0.002$ for AHT). Multiple linear regression analyses show no significant association between BMI and hearing threshold (Table 3).

\section{Association between BMl and ARHL}

The AUROCs for ARHL were analyzed for each participant. For the men, the AUROC value for ARHL was 0.515 (95\% confidence interval $[\mathrm{CI}], 0.488-0.543)$ for BMI $(P=0.335)$. The cutoff value was $\leq 20.7 \mathrm{~kg} / \mathrm{m}^{2}$. The sensitivity and specificity for predicting ARHL were $21.2 \%$ and $84.0 \%$, respectively. For the women, the AUROC value for ARHL was 0.522 (95\% CI, $0.498-0.545)$ for BMI $(P=0.114)$. The cutoff value was $\leq 21.2$

Table 3. Multiple linear regression analysis using body mass index for predicting hearing thresholds

\begin{tabular}{llllllr}
\hline \multirow{2}{*}{ Model } & \multicolumn{2}{c}{ Men } & & \multicolumn{2}{c}{ Women } \\
\cline { 2 - 3 } \cline { 5 - 6 } & NS-B \pm SE & $P$-value & & NS-B \pm SE & $P$-value \\
\hline Model 1 & & & & & \\
Low-Freq & $-0.249 \pm 0.147$ & 0.092 & & $-0.281 \pm 0.117$ & 0.016 \\
Mid-Freq & $-0.135 \pm 0.185$ & 0.466 & & $-0.496 \pm 0.126$ & $<0.001$ \\
High-Freq & $-0.204 \pm 0.152$ & 0.278 & & $-0.616 \pm 0.117$ & $<0.001$ \\
AHT & $-0.190 \pm 0.152$ & 0.211 & & $-0.358 \pm 0.117$ & 0.002 \\
Model 2 & & & & & \\
Low-Freq & $0.039 \pm 0.143$ & 0.785 & & $-0.070 \pm 0.112$ & 0.531 \\
Mid-Freq & $0.183 \pm 0.181$ & 0.312 & & $-0.242 \pm 0.119$ & 0.042 \\
High-Freq & $0.085 \pm 0.185$ & 0.646 & & $-0.315 \pm 0.126$ & 0.012 \\
AHT & $0.103 \pm 0.147$ & 0.483 & & $-0.133 \pm 0.111$ & 0.232 \\
Model 3 & & & & & \\
Low-Freq & $0.101 \pm 0.142$ & 0.478 & & $-0.100 \pm 0.107$ & 0.348 \\
Mid-Freq & $0.201 \pm 0.194$ & 0.299 & & $-0.213 \pm 0.118$ & 0.070 \\
High-Freq & $0.139 \pm 0.207$ & 0.501 & & $-0.239 \pm 0.132$ & 0.071 \\
AHT & $0.154 \pm 0.150$ & 0.304 & & $-0.112 \pm 0.105$ & 0.287 \\
\hline
\end{tabular}

$\mathrm{NS}-\mathrm{B}$, nonstandardized $\mathrm{B}$; Freq, frequency; $\mathrm{AHT}$, average hearing threshold.

Model 1 was unadjusted, model 2 was adjusted for age, and model 3 was adjusted for age, mean daily alcohol intake, smoking, diabetes mellitus, hypertension, exposure to explosive noise, and exposure to occupational noise. $\mathrm{kg} / \mathrm{m}^{2}$. The sensitivity and specificity for predicting ARHL were $19.1 \%$ and $87.1 \%$, respectively.

Unadjusted logistic regression showed that men in the middle and high tertiles had a 1.013- and 0.912-fold increased risk of ARHL compared with participants in the low tertile (Table 4). Women in the middle and high tertiles had a 0.867- and 0.916fold increased risk of ARHL compared with participants in the low tertile. There were no significant differences in the odds ratios in the middle and high tertiles compared with that in the low tertile for either sex. In addition, multivariate logistic regression analyses were adjusted for age, mean daily alcohol intake, smoking, DM, HTN, exposure to explosive noise, and exposure to occupational noise. Despite this adjustment, there were no significant associations between ARHL and BMI tertile.

\section{Subgroup analyses according to age}

The age decreased with an increase in the BMI tertile. We divided both male and female participants into 3 groups according to age (65-69, 70-79, and $\geq 80$ years). The 65-69, 70-79, and $\geq$ 80-year-old groups had 501, 741, and 82 men; and 647, 956,

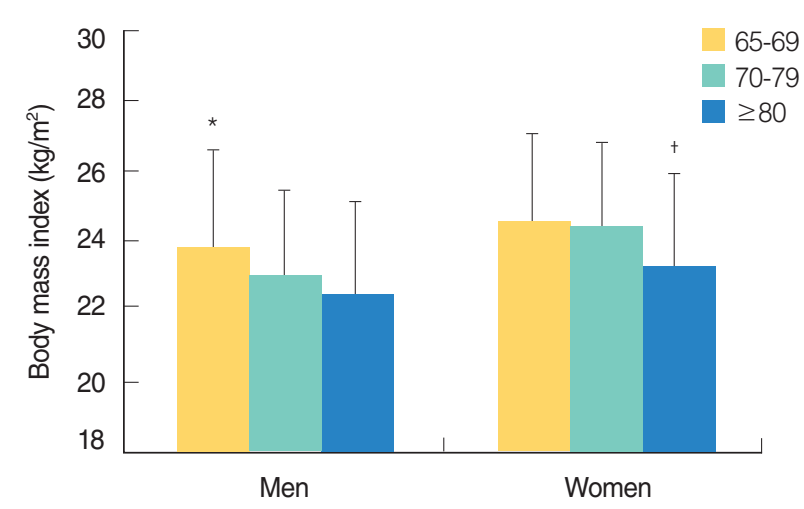

Fig. 3. Body mass index according to age. ${ }^{\star} P<0.05$ versus body mass index in the $70-79$ or $\geq 80$ years old participants. ${ }^{+} P<0.05$ versus body mass index in the 65-69 or 70-79 years old participants.

Table 4. Odds ratio for age-related hearing loss by body mass index tertile

\begin{tabular}{|c|c|c|c|c|c|c|}
\hline \multirow{2}{*}{ Model } & \multicolumn{3}{|c|}{ Men } & \multicolumn{3}{|c|}{ Women } \\
\hline & Low T (ref) & Middle T & High T & Low T (ref) & Middle T & High T \\
\hline \multicolumn{7}{|l|}{ Model 1} \\
\hline OR $(95 \% \mathrm{Cl})$ & - & $1.013(0.777-1.322)$ & $0.912(0.700-1.190)$ & - & $0.867(0.690-1.090)$ & $0.916(0.729-1.150)$ \\
\hline$P$-value & - & 0.922 & 0.498 & - & 0.221 & 0.449 \\
\hline \multicolumn{7}{|l|}{ Model 2} \\
\hline OR $(95 \% \mathrm{Cl})$ & - & $1.115(0.846-1.468)$ & $1.096(0.832-1.445)$ & - & $0.960(0.754-1.222)$ & $1.093(0.858-1.391)$ \\
\hline$P$-value & - & 0.440 & 0.514 & - & 0.471 & 0.471 \\
\hline \multicolumn{7}{|l|}{ Model 3} \\
\hline OR (95\% Cl) & - & $1.115(0.814-1.526)$ & $1.231(0.894-1.695)$ & - & $0.976(0.743-1.282)$ & $1.054(0.800-1.389)$ \\
\hline$P$-value & - & 0.498 & 0.202 & - & 0.864 & 0.709 \\
\hline
\end{tabular}

T, tertile; OR, odds ratio; $\mathrm{Cl}$, confidence interval.

Model 1 was unadjusted, model 2 was adjusted for age, and model 3 was adjusted for age, mean daily alcohol intake, smoking, diabetes mellitus, hypertension, exposure to explosive noise, and exposure to occupational noise. 
and 170 women; respectively. The mean BMI in the 65-69, 7079 , and $\geq 80$-year-old groups in men was $23.8 \pm 2.8,23.0 \pm 3.0$, and $22.5 \pm 2.6 \mathrm{~kg} / \mathrm{m}^{2}$, respectively; and the same in women was $24.6 \pm 3.0,24.4 \pm 3.4$, and $23.2 \pm 3.1 \mathrm{~kg} / \mathrm{m}^{2}$, respectively (Fig. 3). In men, the BMI in the 65-69 years old group was higher than that in the other age groups. In women, the BMI in the $\geq 80$ -year-old group was lower than that in the other age groups. In the men, the AUROC for ARHL was 0.537 (95\% CI, 0.4920.581 ), 0.517 (95\% CI, 0.480-0.553), and 0.569 (95\% CI, 0.454-0.678) for the BMI in the 65-69, 70-79, $\geq 80$ years old participants, respectively $(P=0.153, P=0.439$, and $P=0.378$, respectively). In the women, the AUROC for ARHL was 0.524 (95\% CI, 0.485-0.563), 0.524 (95\% CI, 0.492-0.556), and 0.551 (95\% CI, 0.473-0.627) for the BMI in the 65-69, 70-79, $\geq 80$ years old participants, respectively $(P=0.334, P=0.193$, and $P=0.355$, respectively).

An unadjusted logistic regression showed that, in men, the odd ratios for hearing loss by $1-\mathrm{kg} / \mathrm{m}^{2}$ increase in BMI were 1.046 (95\% CI, 0.981-1.115), 0.987 (95\% CI, 0.939-1.037), and 0.890 (95\% CI, 0.703-1.125) in the 65-69, 70-79, and $\geq$ 80 years old participants, respectively $(P=0.167, P=0.599$, and $P=0.329$, respectively). In women, the odd ratios for hearing loss by $1-\mathrm{kg} / \mathrm{m}^{2}$ increase in BMI were 1.022 (95\% CI, 0.9681.079), 0.979 (95\% CI, 0.942-1.016), and 1.064 (95\% CI, $0.935-1.211)$ in the $65-69,70-79$, and $\geq 80$ years old participants, respectively $(P=0.438, P=0.263$, and $P=0.346$, respectively). Finally, multivariate analyses also showed no significant associations between ARHL and BMI in the 3 age-based groups for either sex.

\section{DISCUSSION}

The present study focused on the association between ARHL and BMI.The prevalence of ARHL was not associated with BMI tertile in either sex. Linear regression analyses showed no association between BMI and hearing thresholds, while logistic regression analyses showed no association between BMI tertile and ARHL.

Previous studies showed an association between obesity and ARHL $[5,14,15]$. The amount or distribution of fat mass induces metabolic disturbances while muscle mass protects from metabolic disturbances [16-18]. Clinical obesity mainly means increase in fat tissue. Fat tissue induces an underproduction of adiponectin, consequently decreasing adiponectin, which may be associated with the development of ARHL [19-22]. BMI is a classic indicator for obesity. However, BMI cannot distinguish between fat and muscle mass, and cannot evaluate the distribution of fat mass.

Some studies have shown that BMI is positively associated with the development of ARHL [5-7,9,23]. This hypothesis is based on the belief that the hearing threshold is associated with vasculopathies in the metabolic problem and that BMI is an important marker for metabolic diseases [4]. Therefore, the increase in BMI may be related to hearing impairment. However, some studies have suggested that BMI is not an optimal marker for predicting metabolic diseases [24-26]. Obese individuals can be divided into 2 categories: the metabolically healthy obese and the metabolically unhealthy obese. In addition, individuals with normal BMI can have metabolic problems. Wildman et al. [25] showed that there is a high prevalence of metabolic abnormalities in individuals with a normal BMI or obese individuals who are metabolically healthy. BMI cannot differentiate between individuals with metabolically healthy obesity or with a normal BMI and a high metabolic risk.

Previous studies had some limitations. Some studies demonstrated the association between 2 variables in only women [7,23]. Other studies defined the high BMI group as participants with a very high BMI level (>95th percentile) or they did not show the association between 2 variables in high frequency [6,23]. A large cohort study that enrolled 68,421 participants showed an association between ARHL and BMI, but the hearing threshold was evaluated by questionnaire. The present study enrolled a large number of participants, and the participants were divided into 3 groups according to their BMI level. The ARHL was evaluated using pure tone audiometry, and the patients with congenital or acquired abnormalities were excluded using comprehensive ear examinations.

In the present study, univariate analysis showed no association between the prevalence of ARHL and BMI tertile in either sex. We analyzed the associations between BMI and hearing thresholds as continuous variables (low-, mid-, high-frequency, or AHT) and ARHL as a categorical variable. There were no significant associations in these analyses. Although the low-frequency value in men and the mid- and high-frequency values in women decreased as BMI tertile increased, the multivariate analyses adjusted for age showed no significant association between BMI tertile and these values in either sex. The AUROC values for ARHL were 0.515 for men and 0.522 for women. BMI did not have a significant value for predicting ARHL and the AUROC values were very small. The sensitivity was low in both sexes. Therefore, the use of BMI as a covariate may be unnecessary for the correction of metabolic disturbances for ARHL, and BMI may be replaced by other metabolically active parameters such as fat mass index, waist circumference, or visceral fat area.

There were some issues regarding the association between $\mathrm{BMI}$ and age. BMI is a risk factor for mortality [27]. Increasing age is associated with decrease in muscle mass, and the elderly population with a high baseline BMI is under risk of mortality. Therefore, reference BMI in the elderly population is different from that in the nonelderly population. A previous report showed that the mean BMI in the 65-69, 70-79, and $\geq 80$ years old elderly population was $29.5,28.8$, and $27.2 \mathrm{~kg} / \mathrm{m}^{2}$, respectively, in men; and 29.6, 29.5, and $26.7 \mathrm{~kg} / \mathrm{m}^{2}$, respectively, in 
women [10]. These contradicting results regarding the association between BMI and HL may be associated with different age criteria. This issue also reveals the difficulty in applying the same criteria for elderly and nonelderly populations. Therefore, we tried to decrease the effect of age in our study. Our data showed a difference in the baseline BMI by age, but the subgroup analysis according age also showed no association between BMI and ARHL in the 3 age-based groups for either sex.

Our study enrolled participants from a wide age range and from both sexes. The baseline BMI is different according to sex or age, and the association may be different according to participants' age or sex. Therefore, we tried to decrease these biases by dividing the participants into groups by sex or age. We found no association between BMI and HL using various statistical methods or hearing indicators (i.e., hearing thresholds as continuous variable and hearing loss as a categorical variable). We think that these subgroup analyses and various statistical methods are useful to identify the nonassociation between 2 variables.

Some authors have evaluated the association between hearing thresholds and metabolic parameters other than BMI. Kim et al. [28] investigated the association between visceral fat area measured using computed tomography and hearing threshold. Kang et al. [29] showed an association between metabolic syndrome and hearing thresholds. Their study also showed that each metabolic syndrome or insulin resistance component was associated with hearing thresholds. Hwang et al. [8] showed that waist circumference as a marker of central obesity is an independent risk factor of ARHL and that waist circumference was more important than BMI as a risk factor of ARHL. In addition, a prospective study demonstrated that waist circumference was associated with hearing impairment in subjects aged 48-92 years [30]. BMI may be replaced with the aforementioned parameters, but further investigations will be needed to determine whether they are superior to BMI.

There were a few limitations in this study. First, the study was limited by its cross sectional nature. Second, the present study included an ethnically homogenous population. Third, this study did not evaluate sensitive components of hearing problems such as speech discrimination. Further prospective analysis, including follow-up data and speech discrimination, will be needed to evaluate a possible strong correlation between the 2 variables.

In conclusion, BMI is not advantageous for the prediction of ARHL. In future epidemiological studies, BMI as a covariate of obesity may be replaced by other active metabolic parameters that have better predictive ability of ARHL than BMI.

\section{CONFLICT OF INTEREST}

No potential conflict of interest relevant to this article was reported.

\section{ACKNOWLEDGMENTS}

This research was supported by Basic Science Research Program through the National Research Foundation of Korea (NRF) funded by the Ministry of Science, ICT \& Future Planning (2014R1A1A3049993).

\section{REFERENCES}

1. Huang Q, Tang J. Age-related hearing loss or presbycusis. Eur Arch Otorhinolaryngol. 2010 Aug;267(8):1179-91.

2. Bao J, Ohlemiller KK. Age-related loss of spiral ganglion neurons. Hear Res. 2010 Jun;264(1-2):93-7.

3. Bielefeld EC, Tanaka C, Chen GD, Henderson D. Age-related hearing loss: is it a preventable condition? Hear Res. 2010 Jun;264(12):98-107.

4. Fetoni AR, Picciotti PM, Paludetti G, Troiani D. Pathogenesis of presbycusis in animal models: a review. Exp Gerontol. 2011 Jun;46(6): 413-25.

5. Fransen E, Topsakal V, Hendrickx JJ, Van Laer L, Huyghe JR, Van Eyken E, et al. Occupational noise, smoking, and a high body mass index are risk factors for age-related hearing impairment and moderate alcohol consumption is protective: a European populationbased multicenter study. J Assoc Res Otolaryngol. 2008 Sep;9(3): 264-76.

6. Helzner EP, Patel AS, Pratt S, Sutton-Tyrrell K, Cauley JA, Talbott E, et al. Hearing sensitivity in older adults: associations with cardiovascular risk factors in the health, aging and body composition study. J Am Geriatr Soc. 2011 Jun;59(6):972-9.

7. Curhan SG, Eavey R, Wang M, Stampfer MJ, Curhan GC. Body mass index, waist circumference, physical activity, and risk of hearing loss in women. Am J Med. 2013 Dec;126(12):1142.e1-8.

8. Hwang JH, Wu CC, Hsu CJ, Liu TC, Yang WS. Association of central obesity with the severity and audiometric configurations of age-related hearing impairment. Obesity (Silver Spring). 2009 Sep;17(9): 1796-801.

9. Shargorodsky J, Curhan SG, Eavey R, Curhan GC. A prospective study of cardiovascular risk factors and incident hearing loss in men. Laryngoscope. 2010 Sep;120(9):1887-91.

10. Centre for Disease Control and Prevention. Anthropometric reference data for children and adults: United States, 2007-2010. Data from the National Health and Nutrition Examination Survey [Internet]. Hyattsville (ML): U.S. Department of Health and Human Services, Centers for Disease Control and Prevention, National Center for Health Statistics; 2012 [cited 2015 Aug 5]. Available from: http:// www.cdc.gov/nchs/data/series/sr_11/sr11_252.pdf.

11. Rehm J, Room R, Monteiro M, Gmel G, Graham K, Rehn N, et al. Alcohol use. In: Ezzati M, Lopez AD, Rodgers A, Murray CJL editors. Comparative quantification of health risks: global and regional burden of disease attributable to selected major risk factors. Geneva: World Health Organization; 2004. p. 959-1108.

12. National Health Information Portal. Alcohol drinking [Internet]. Sejong: Ministry of Health and Health; 2015 [cited 2015 Aug 5]. Available from: http://health.mw.go.kr/HealthPromotionArea/HealthInfo/View.do?idx $=5800 \&$ subIdx $=4 \&$ searchCate $=\&$ searchType $=\&$ sear chKey=\&pageNo=1.

13. Kang JW, Choi HS, Kim K, Choi JY. Dietary vitamin intake correlates with hearing thresholds in the older population: the Korean National Health and Nutrition Examination Survey. Am J Clin Nutr. 2014 Jun;99(6):1407-13. 
14. Gates GA, Cobb JL, D'Agostino RB, Wolf PA. The relation of hearing in the elderly to the presence of cardiovascular disease and cardiovascular risk factors. Arch Otolaryngol Head Neck Surg. 1993 Feb;119(2):156-61.

15. Barrenas ML, Jonsson B,Tuvemo T, Hellstrom PA, Lundgren M. High risk of sensorineural hearing loss in men born small for gestational age with and without obesity or height catch-up growth: a prospective longitudinal register study on birth size in 245,000 Swedish conscripts. J Clin Endocrinol Metab. 2005 Aug;90(8):4452-6.

16. Atlantis E, Martin SA, Haren MT, Taylor AW, Wittert GA; Members of the Florey Adelaide Male Ageing Study. Inverse associations between muscle mass, strength, and the metabolic syndrome. Metabolism. 2009 Jul;58(7):1013-22.

17. Liu P, Ma F, Lou H, Liu Y.The utility of fat mass index vs. body mass index and percentage of body fat in the screening of metabolic syndrome. BMC Public Health. 2013 Jul;13:629.

18. Despres JP, Moorjani S, Lupien PJ,Tremblay A, Nadeau A, Bouchard C. Regional distribution of body fat, plasma lipoproteins, and cardiovascular disease. Arteriosclerosis. 1990 Jul-Aug;10(4):497-511.

19. Kishida K, FunahashiT, Shimomura I. Adiponectin as a routine clinical biomarker. Best Pract Res Clin Endocrinol Metab. 2014 Jan; 28(1):119-30.

20. Hwang JH, Hsu CJ, Liu TC, Yang WS. Association of plasma adiponectin levels with hearing thresholds in adults. Clin Endocrinol (Oxf). 2011 Nov;75(5):614-20.

21. Tanigawa T, Shibata R, Ouchi N, Kondo K, Ishii M, Katahira N, et al. Adiponectin deficiency exacerbates age-related hearing impairment. Cell Death Dis. 2014 Apr;5:e1189.

22.Wu CC, Tsai CH, Lu YC, Lin HC, Hwang JH, Lin YH, et al. Contribution of adiponectin and its type 1 receptor to age-related hearing impairment. Neurobiol Aging. 2015 Jun;36(6):2085-93.
23. Lalwani AK, Katz K, Liu YH, Kim S, Weitzman M. Obesity is associated with sensorineural hearing loss in adolescents. Laryngoscope. 2013 Dec;123(12):3178-84.

24. Meigs JB, Wilson PW, Fox CS, Vasan RS, Nathan DM, Sullivan LM, et al. Body mass index, metabolic syndrome, and risk of type 2 diabetes or cardiovascular disease. J Clin Endocrinol Metab. 2006 Aug;91(8):2906-12.

25. Wildman RP, Muntner P, Reynolds K, McGinn AP, Rajpathak S, Wylie-Rosett J, et al. The obese without cardiometabolic risk factor clustering and the normal weight with cardiometabolic risk factor clustering: prevalence and correlates of 2 phenotypes among the US population (NHANES 1999-2004). Arch Intern Med. 2008 Aug; 168(15):1617-24

26. Karelis AD. Metabolically healthy but obese individuals. Lancet. 2008 Oct;372(9646):1281-3.

27. Jee SH, Sull JW, Park J, Lee SY, Ohrr H, Guallar E, et al. Body-mass index and mortality in Korean men and women. N Engl J Med. 2006 Aug;355(8):779-87.

28. Kim TS, Park SW, Kim do Y, Kim EB, Chung JW, So HS. Visceral adipose tissue is significantly associated with hearing thresholds in adult women. Clin Endocrinol (Oxf). 2014 Mar;80(3):368-75.

29. Kang SH, Jung da J, Cho KH, Park JW, Yoon KW, Do JY.The association between metabolic syndrome or chronic kidney disease and hearing thresholds in Koreans: the Korean National Health and Nutrition Examination Survey 2009-2012. PLoS One. 2015 Mar;10 (3): e0120372.

30. Cruickshanks KJ, Nondahl DM, Dalton DS, Fischer ME, Klein BE, Klein R, et al. Smoking, central adiposity, and poor glycemic control increase risk of hearing impairment. J Am Geriatr Soc. 2015 May;63 (5):918-24. 